\title{
MRI-conditional pacemakers: current perspectives
}

This article was published in the following Dove Press journal:

Medical Devices: Evidence and Research

7 May 2014

Number of times this article has been viewed

\author{
António M Ferreira ${ }^{1,2}$ \\ Francisco Costa ${ }^{2}$ \\ António Tralhão ${ }^{2}$ \\ Hugo Marques ${ }^{3}$ \\ Nuno Cardim' \\ Pedro Adragão ${ }^{1,2}$ \\ 'Cardiology Department, \\ Hospital da Luz, ${ }^{2}$ Cardiology \\ Department, Hospital Santa Cruz- \\ CHLO, ${ }^{3}$ Radiology Department, \\ Hospital da Luz, Lisbon, Portugal
}

Correspondence: António M Ferreira Hospital da Luz, Avenida Lusíada I00, I500-650 Lisbon, Portugal

Tel +35 I 2I 7104400

$\mathrm{Fax}+351217104409$

Email antonio.ferreira@hospitaldaluz.pt

\begin{abstract}
Use of both magnetic resonance imaging (MRI) and pacing devices has undergone remarkable growth in recent years, and it is estimated that the majority of patients with pacemakers will need an MRI during their lifetime. These investigations will generally be denied due to the potentially dangerous interactions between cardiac devices and the magnetic fields and radiofrequency energy used in MRI. Despite the increasing reports of uneventful scanning in selected patients with conventional pacemakers under close surveillance, MRI is still contraindicated in those circumstances and cannot be considered a routine procedure. These limitations prompted a series of modifications in generator and lead engineering, designed to minimize interactions that could compromise device function and patient safety. The resulting MRI-conditional pacemakers were first introduced in 2008 and the clinical experience gathered so far supports their safety in the MRI environment if certain conditions are fulfilled. With this technology, new questions and controversies arise regarding patient selection, clinical impact, and cost-effectiveness. In this review, we discuss the potential risks of MRI in patients with electronic cardiac devices and present updated information regarding the features of MRIconditional pacemakers and the clinical experience with currently available models. Finally, we provide some guidance on how to scan patients who have these devices and discuss future directions in the field.
\end{abstract}

Keywords: pacemakers, magnetic resonance imaging, MRI, MRI-conditional devices, safety

\section{Introduction}

Magnetic resonance imaging (MRI) is a versatile imaging technique capable of producing high quality images of the human body. MRI provides excellent spatial resolution and unparalleled tissue characterization without exposing patients to the potential risks of ionizing radiation and iodinated contrast agents. Beyond morphological assessment, MRI is capable of providing valuable information on tissue perfusion, function, and metabolism. For these reasons, MRI has become the imaging modality of choice in a wide spectrum of clinical situations, and is now used for the diagnosis, staging, and follow-up of numerous diseases, including a large number of neurological, musculoskeletal, oncological, and cardiovascular disorders. As a consequence, the number of MRI scans has grown strongly in recent decades. In the USA, the number of procedures rose from 7.7 million in 1993 to nearly 22 million in 2002. ${ }^{1}$ More recent data indicate that, in 2011, 32 million scans were performed in that country. ${ }^{2}$ Worldwide, it is estimated that approximately 60 million scans are performed each year. ${ }^{3}$ The use of MRI is likely to continue to grow due to a combination of an 
aging population and the expanding indications and increasing accessibility to this technique.

Parallel to the growth of MRI, the number of patients with implantable cardiac devices, including pacemakers, implantable cardioverter defibrillators, and cardiac resynchronization therapy, has been steadily increasing. Between 1993 and 2009, 2.9 million patients received permanent pacemakers in the USA and overall use increased by more than $50 \% .{ }^{4} \mathrm{~A}$ worldwide survey showed that, in 2009 alone, more than one million pacemakers were implanted, and virtually all countries reported increases in implant numbers. ${ }^{5}$ The combination of these two growing phenomena results in an estimated $50 \%-75 \%$ probability of a patient needing an MRI over the lifetime of the device. ${ }^{6}$ These patients will generally see their MRI studies denied due to safety concerns. ${ }^{7-9}$ This "clash of technologies" thus creates a paradoxical effect in which application of a useful technique is limited by the presence of another technology in the same patient. ${ }^{10}$ The recent introduction of MRI-conditional pacemakers overcomes this important limitation of MRI and cardiac pacing, allowing physicians to take full advantage of this imaging technique in the growing number of patients with cardiac devices. In this review, we discuss the potential hazards of the interactions between conventional pacemakers and the MRI environment, and present updated information regarding the features of MRI-conditional pacemakers and clinical experience with currently available models. Finally, we provide some advice on how to scan patients with these devices and discuss future directions in the field.

\section{Potential risks of MRI in patients with conventional pacemakers}

The risks associated with MRI can be broadly categorized by the interaction between the pacemaker system and three essential components of MRI, ie, the static magnetic field, gradient magnetic fields, and radiofrequency energy. ${ }^{11}$

\section{Static magnetic field}

Most modern clinical MRI scanners operate at static magnetic fields of 1.5 or 3 tesla $(T)$, roughly corresponding to 30,000 and 60,000 times the strength of the earth's magnetic field, respectively. The greatest risk from this strong magnetic field is the attraction of ferromagnetic objects into the scanner causing movement, torque, dislodgment, or even a "projectile effect" that can result in patient injury and damage to the MRI system. However, except for older devices with a higher content of ferromagnetic material (approved by the US Food and Drug Administration [FDA] prior to 1998), the mechanical forces exerted on pacemaker systems are usually negligible at $1.5 \mathrm{~T} .{ }^{12}$ Of greater concern is the possibility of magnetic sensor activation and unpredictable reed-switch behavior, causing the device to revert to asynchronous pacing. ${ }^{13,14}$ The static magnetic field is also responsible for the magnetohydrodynamic effect. Since blood contains electrically charged ions, its flow in the presence of a powerful static magnetic field produces small voltages, which are superimposed on the patient's electrocardiogram. This may simulate life-threatening arrhythmias and produce other electrocardiographic changes, including T-wave abnormalities and elevation of the ST segment. ${ }^{15}$ The magnetohydrodynamic effect hinders electrocardiographic monitoring during scanning, ${ }^{16}$ and may lead to inappropriate inhibition of pacemaker function. ${ }^{17}$ The stronger the magnetic field, the greater the magnitude of this phenomenon.

\section{Gradient magnetic fields}

During MRI scanning, gradient coils create additional, linearly varying magnetic fields that add or subtract from the main magnetic field. Gradient magnetic fields are essential for spatial encoding and are measured in millitesla per meter $(\mathrm{mT} / \mathrm{m})$. High performance gradient coils used in MRI are typically capable of producing gradient magnetic fields of $20-100 \mathrm{mT} / \mathrm{m}$ or higher for a $1.5 \mathrm{~T}$ scanner. These gradients are repeatedly and rapidly turned on and off (the slew rate of a gradient system is a measure of how quickly this can happen). These rapidly changing magnetic fields can induce electrical currents in pacemaker leads, causing oversensing, undersensing, or even life-threatening arrhythmias. ${ }^{8,13,18,19}$

\section{Radiofrequency energy}

In order to produce images, MRI scanners use short bursts of electromagnetic waves at very specific frequencies (radiofrequency pulses), which interact with spinning protons. At the end of each pulse, protons return to their previous spinning orientation and, in doing so, release energy in the form of radiofrequency waves that are used for reconstructing an image. During this process, the body will absorb some of the radiofrequency energy causing resistive heating. The specific absorption rate (measured in $\mathrm{W} / \mathrm{kg}$ ) is the dosimetric term used to describe the amount of radiofrequency energy employed during an MRI scan. Pacemaker leads can act as "antennae" which concentrate this radiofrequency energy, producing heat and electrical currents, ${ }^{20}$ which may cause tissue destruction at the lead tip ${ }^{21}$ myocardial stimulation (including life-threatening arrhythmias), and damage to the pulse generator circuitry and battery. ${ }^{22-24}$ This may produce pacemaker reset, battery depletion, and adverse 
effects on sensing, pacing thresholds, and lead impedances, causing inappropriate pacing acceleration or inhibition. ${ }^{10,25}$ Abandoned or fractured leads are especially prone to tip heating. ${ }^{26,27}$

\section{MRI in patients with conventional pacemakers: feasible?}

Given the potential risks of the interactions between the MRI environment and conventional pacemakers, these devices are classified as MRI-unsafe and their presence has long been considered a contraindication for MRI. Over the years, these safety concerns have been substantiated by at least 17 supposed MRI-associated deaths among patients with pacemakers. ${ }^{28}$ This number is probably an underestimation of the real number of fatalities, since there are several cases of patients with a cardiac pacemaker who died after exposure to MRI that have never been reported in the medical literature but have come to light via the general press or the legal system. ${ }^{29}$ However, it should also be noted that a firm causal relationship has seldom been established, and that most of these deaths occurred in patients with older pacemaker models undergoing MRI without appropriate programming or physician-supervised monitoring. ${ }^{28,30}$

Despite all safety concerns, many pacemaker patients without an acceptable alternative imaging modality have undergone MRI uneventfully. ${ }^{31-45}$ A recent review of 15 human studies involving 1,419 MRI scans (mostly nonthoracic) reported no serious adverse events, although $65 \%$ of these were performed in patients with MRI-conditional devices. ${ }^{30}$ Without accounting for these, $49 \%$ of the examinations did not result in any significant changes in pacemaker function after the scan. ${ }^{30}$ A multicenter registry of clinically indicated nonthoracic MRI at $1.5 \mathrm{~T}$ for patients with non-MRI-conditional pacemakers and implantable cardioverter defibrillators implanted after 2001 is currently underway. ${ }^{46}$ This registry is expected to encompass up to 1,500 examinations, provide further insights on the risks of MRI in such conditions, and hopefully validate a clinical protocol for screening and scanning these patients, who will for many years constitute the majority of those with implanted cardiac devices.

It should be emphasized that special precautions were taken in these studies, including careful patient selection and device programming, rigorous monitoring, reanimation readiness during the procedure, and exclusion of thoracic MRI (in most cases). So, performing MRI in patients with conventional pacemakers cannot be considered a routine procedure. ${ }^{7,8,47-49}$ Moreover, the number of patients examined in these conditions is still largely insufficient to determine safety, and possible long-term effects are unknown. ${ }^{50}$ Rather than establishing the clinical safety of MRI in patients with non-MRI-conditional devices, these data have shown that the risk may be lower than previously thought if a number of conditions are met and special precautions are taken. ${ }^{51}$ A practical implication of these findings is that, when the information provided by MRI seems vital for the management of a patient with a non-MRI-conditional pacemaker, the risk of scanning under close surveillance is probably lower than the risk of removing existing leads, since lead extraction is associated with a significant risk of complications. ${ }^{52,53}$

Position statements issued by the American Heart Association and the European Society of Cardiology continue to advise against MRI in patients with conventional pacemakers, although they do not establish it as an absolute contraindication. ${ }^{7,8}$ The American Heart Association guidelines discourage MRI in non-pacemaker-dependent patients, except in cases with a strong clinical indication and in which the benefits clearly outweigh the risks. ${ }^{7}$ Among pacemakerdependent patients, MRI should not be performed unless there are highly compelling circumstances. ${ }^{7}$ The European guidelines also strongly recommend against MRI in nonpacemaker-dependent patients, except in the presence of a documented, extremely serious, life-threatening, or severely "quality of life-limiting" condition. ${ }^{8}$ In pacemaker-dependent patients, the indication for MRI should be seriously reconsidered if the underlying rhythm is too slow, and the threshold for imaging and safety requirements are higher. ${ }^{8}$ Both sets of guidelines restrict MRI in patients with conventional pacemakers to specialized centers with specific expertise and equipment for close monitoring. In 2013, the American College of Radiology issued a Guidance Document on Safe MR Practices, ${ }^{54}$ where a case-by-case and site-by-site appraisal is recommended before scanning patients with nonMRI-conditional devices. These guidelines also emphasize the need for careful risk-benefit assessment and close collaboration between radiology and cardiology staff and industry representatives of the device manufacturers.

\section{MRI-conditional pacemakers: "safe by design"}

The increasing importance of MRI as a diagnostic tool and the limitations imposed by conventional pacemakers prompted a large amount of research and efforts to develop devices suitable for use in this environment. Gathering the knowledge collected in in vitro, animal, and human studies, pacemaker manufacturers introduced a significant number 
of modifications to their devices. ${ }^{55}$ The most important are specified below and summarized in Table 1 .

\section{Minimization of ferromagnetic content}

The reduction of ferromagnetic content is intended to decrease magnetic attraction and also minimize susceptibility artifacts produced by the pacemaker system (Figure 1). This can be achieved through the use of nonferromagnetic materials, which have to be appropriately conductive, durable, and biocompatible. The leads are made of nonmagnetic materials. ${ }^{10}$

\section{Replacement of reed switches}

Conventional pacemakers have reed switches devised to revert the device to asynchronous pacing mode (DOO or VOO) when a magnet is placed over the impulse generator. This feature is useful to avoid the effects of electromagnetic interactions such as the ones that occur when electrocautery is used during surgery. Reed switch behavior in the MRI environment may vary with the strength of the magnetic field and the orientation of the reed switch, and is essentially unpredictable. ${ }^{14}$ To overcome this problem, reed switches have been replaced by solid-state Hall sensors, which have more predictable behavior when exposed to magnetic fields. ${ }^{3,10}$

\section{Lead design}

The goal is to minimize the amount of heat and electrical currents that are induced on the leads by the electromagnetic energy used in MRI. To achieve this, the resonant frequency should be avoided to prevent the lead from acting as a receiver of electromagnetic impulses. This was accomplished by modifications in lead geometry that included changing the winding pattern of the filaments that compose the inner lead coil, thus limiting the radiofrequencies that can conduct through the filaments. ${ }^{10,56,57}$

Table I Main modifications introduced in MRI-conditional pacing systems

\begin{tabular}{ll}
\hline $\begin{array}{l}\text { Modification } \\
\text { Reduction in ferromagnetic } \\
\text { components }\end{array}$ & Purpose \\
$\begin{array}{l}\text { Replacement of reed switch by } \\
\text { Hall sensor }\end{array}$ & $\begin{array}{l}\text { Reduce magnetic attraction } \\
\text { and susceptibility artifacts } \\
\text { Lead coil design and insulation }\end{array}$ \\
switch behavior \\
Filter circuitry & $\begin{array}{l}\text { Minimize lead heating and } \\
\text { electrical current induction }\end{array}$ \\
Dedicated pacemaker programming & $\begin{array}{l}\text { Prevent damage to internal } \\
\text { power supply }\end{array}$ \\
& $\begin{array}{l}\text { Prevent inappropriate } \\
\text { pacemaker inhibition } \\
\text { Prevent competing rhythms }\end{array}$ \\
\hline
\end{tabular}

Abbreviation: MRI, magnetic resonance imaging.

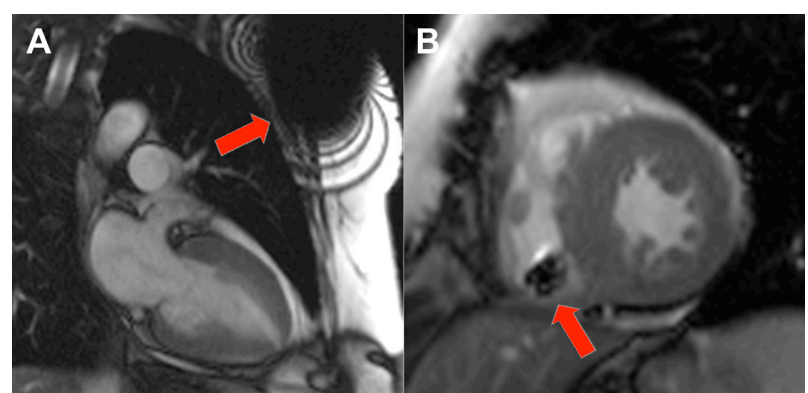

Figure I Balanced steady-state free precession (b-SSFP) cine images of the heart in a patient with an implanted magnetic resonance imaging-conditional pacemaker. Notes: Note the susceptibility artifacts from the pulse generator in left ventricular 2-chamber view (A) and from the right ventricular lead in short-axis view (B). Despite being clearly apparent, these artifacts don't usually hinder diagnostic interpretation, except when the region of interest is in the proximity of the pacemaker generator.

Lead tip coating and bipolar lead designs were also used to minimize electromagnetic interference..$^{10}$ It should be emphasized that MRI-conditional pacemakers are designed to be used only with compatible MRI-conditional leads in accordance with the manufacturer's conditions. So, except for some pacing leads that were proven to be "backwards MRI-compatible", connecting an MRI-conditional generator to pre-existing conventional leads is insufficient to make the system MRI-conditional, even though this may theoretically minimize the chances of power-on reset during an MRI scan.

\section{Special pacemaker circuitry}

MRI-conditional pacemakers have been equipped with special filters that limit the transfer of certain frequencies and dissipate energy, reducing the risk of damage to the internal power supply and circuitry. Generator shielding has also been improved to minimize the transfer of electromagnetic energy. ${ }^{10}$

\section{Dedicated pacemaker programming}

Dedicated programming is an essential feature of MRIconditional pacemakers. An "MRI mode" must be switched on before entering the scanner, and switched off immediately afterwards. Specific programming pathways were developed to assist in the choice between asynchronous versus nonstimulation modes (a decision that still requires arrhythmia expertise). Programming also includes mandatory system-integrity checks, increased pacing output during MRI scanning, and effortless restoration of prescan program states and values. ${ }^{51}$

\section{Growing portfolio of MRI- conditional pacemakers and clinical experience so far Medtronic ${ }^{\circledR} \mathrm{MRI}$-conditional pacemakers}

Medtronic (Minneapolis, MN, USA) was the first company to introduce an MRI-conditional pacemaker in 2008 
(named EnRhythm ${ }^{\mathrm{TM}}$ in Europe, Revo MRITM in the USA). A second generation of MRI-conditional pacemakers (Ensura MRITM and Advisa MRITM) was introduced in 2011, overcoming some of the limitations of the first models. These limitations include an upper rate limit of 150 beats per minute and the inability to be used in unipolar mode (sometimes useful to deal with sensing or threshold problems). All these dual chamber devices are approved for whole body scans and include comprehensive arrhythmia detection and software designed to minimize ventricular pacing. Medtronic provides MRI-conditional leads with active and passive fixation. The active fixation lead 5086 is based on the older 5076 CapSureFix Novus ${ }^{\text {TM }}$ with a two-filar inner coil designed to obtain higher inductance and reduce lead tip heating. Recently, the 5076 lead received CE (Conformité Européenne) marking for backwards MRI compatibility, meaning that patients with older pacemaker systems using this lead can be upgraded to MRI-conditional systems with a simple box change. The passive fixation 5.3F isodiametric lead (CapSure Sense ${ }^{\mathrm{TM}}$ ) also received CE marking for backwards MRI compatibility.

The Medtronic EnRhythm SureScan ${ }^{\mathrm{TM}}$ pacemaker was first tested outside the MRI environment, where it was compared in terms of efficacy and safety with a conventional dual-chamber pacemaker system with active fixation leads. In the first of two single-center studies, procedural and fluoroscopy times were longer for the MRI-conditional device, but implantation success rate and clinical performance did not differ in the 107 patients evaluated.$^{58}$ A subsequent study did not find significant differences in reoperation rates or shortterm clinical performance between conventional pacemakers and the new pacemaker system with the newly designed leads (5086 CapSureFix). ${ }^{59}$

The first prospective, randomized multicenter study assessing the efficacy and safety of an MRI-conditional pacemaker in the MRI environment was published in 2011. Wilkoff et al assessed 464 patients implanted with the Medtronic Revo SureScan pacemaker randomized to undergo $(n=258)$ or not undergo $(n=206)$ a nonmedically indicated brain and lumbar MRI in the $9-12$ weeks post-implantation. ${ }^{60}$ MRI scan restrictions were similar to those used in protocols for conventional pacemakers, ie, exclusion of thoracic scanning, static magnetic field strength limited to $1.5 \mathrm{~T}$, maximum specific absorption rate of $2 \mathrm{~W} / \mathrm{kg}$, and maximum gradient slew rate of $200 \mathrm{mT} / \mathrm{m}$ per second. There were no complications (primary safety endpoint) and no MRI-attributed pacemaker sensing or threshold changes (primary efficacy endpoint) in patients who underwent scans. These included subjects with and without pacemaker dependency, using the asynchronous mode $(\mathrm{n}=158)$ and no pacing with a continuous intrinsic rhythm during scanning $(n=67)$.

More recently, the second-generation Medtronic Advisa MRITM SureScan Pacemaker and CapSureFix MRI SureScan lead were studied in a clinical trial where 263 patients were randomized in a 2:1 ratio to undergo 16 chest and head scans at $1.5 \mathrm{~T}$ between 9 and 12 weeks after pacemaker implantation or not to undergo MRI. ${ }^{61}$ There were no MRI-related complications during or after MRI in the scanned subjects. Differences in pacing capture threshold values from pre-MRI up to one month post-MRI were minimal and similar between the MRI and control groups. This device has subsequently received CE marking in Europe and was also approved by the FDA without positioning restrictions for MRI scans or limitations of body parts scanned, overcoming previous limitations on chest imaging.

\section{St Jude Medical ${ }^{\circledR} \mathrm{MRI}$-conditional pacemakers}

The Accent MRI ${ }^{\mathrm{TM}}$ conditional pacemaker, available in single and dual chamber versions, was introduced in the European market in 2011 and is currently awaiting FDA approval. In Europe, this device is approved for full body scans (no zone restrictions) at $1.5 \mathrm{~T}$ when used in combination with Tendril ${ }^{\mathrm{TM}}$ MRI leads. St Jude (St Paul, MN, USA) also introduced a hand-held MRI Activator ${ }^{\mathrm{TM}}$ that allows quick enabling and disabling of preapproved MRI settings to facilitate the MRI scanning workflow (these can be preprogrammed by the physician at any follow-up visit). The Accent MRI-conditional pacemaker features full bradyarrhythmia therapy and is also compatible with the St Jude Merlin ${ }^{\mathrm{TM}}$ home monitoring system. The Tendril ${ }^{\mathrm{TM}}$ MRI lead has a coaxial design and 6.6 $\mathrm{F}$ body (requiring an $8 \mathrm{~F}$ introducer). It is based on standard Tendril ${ }^{\mathrm{TM}}$ lead inner and outer coils with additional silicone inner tubing and Optim ${ }^{\mathrm{TM}}$ insulation, including a second filter to prevent tissue heating and unintended cardiac stimulation. A soft silicon tip was also introduced to reduce the chances of cardiac perforation, addressing previous concerns regarding increased stiffness of MRI-conditional leads compared with conventional leads. ${ }^{62}$

\section{Boston Scientific ${ }^{\circledR}$ MRI-conditional pacemakers}

The Ingenio ${ }^{\mathrm{TM}}$ and Advantio ${ }^{\mathrm{TM}}$ Boston Scientific (Natick, MA, USA) MRI pacemakers are available in single and dual chamber with CE approval. The devices are based on the Ingenio conventional pacemaker and are compatible with the Latitude ${ }^{\mathrm{TM}}$ remote monitoring system. They include a programmable MRI timer designed to return pacemaker 
settings back to normal after the scan. FINELINETM II 5.1F active fixation leads received backwards MRI-conditional approval. A multicenter, nonrandomized single-arm study (INFINITE MRI $)^{63}$ to collect data on the Boston Scientific MRI-conditional pacing system (consisting of an Ingenio MRI or Advantio MRI pacemaker with FINELINETM II Sterox or FINELINETM II Sterox EZ leads) is presently underway.

\section{Biotronik $^{\circledR}$ MRI-conditional pacemakers}

The Evia ${ }^{\mathrm{TM}}$ and Estella ${ }^{\mathrm{TM}}$ MRI-conditional pacemakers, available in single and dual chamber models, are approved in Europe for MRI scanning at $1.5 \mathrm{~T}$ with isocenter positioning above the eye level and below the level of the greater trochanters (in practice, this limitation usually precludes thoracic and upper abdominal imaging, but not head or lower extremity scans). Biotronik (Berlin, Germany) recommends limiting scan duration to 30 minutes and total device lifetime scan time to 10 hours. Both devices are compatible with a remote monitoring system.

A prospective feasibility pilot study assessing 30 patients with the Biotronik Evia SR-T and DR-T pacemaker with Safio $^{\text {TM }}$ S53/S60 screw-in leads showed encouraging results. ${ }^{64}$ All patients underwent MRI scans of the head and lumbar spine and were evaluated before, immediately after, and at one and 3 months post-MRI. There were no MRI-related adverse events, and no significant differences in lead parameters were identified. These findings await confirmation from a multicenter, randomized clinical trial designed to evaluate the one-month rate of adverse events with the Biotronik ProMRI ${ }^{\mathrm{TM}}$ Entovis ${ }^{\mathrm{TM}}$ MRI-conditional pacing system, which has finished the recruitment phase $(n=245)$ and is expected to reach completion in early 2014. A trial extension aiming to evaluate the safety of this device without exclusion zones has recently received FDA approval. ${ }^{65}$

\section{Sorin Group (Milano, Italy) MRI-conditional pacemaker}

The KORA 100 MRI-conditional pacemaker is available in Europe in single and dual chamber models. This device, built on the REPLYTM pacemaker platform, includes a filter between the lead and device electronics and received CE mark approval for MRI scanning at $1.5 \mathrm{~T}$ with chest exclusion. The KORA 100 was designed for implantation with MRI-conditional BEFLEX ${ }^{\mathrm{TM}}$ leads. Sorin (Milan, Italy) developed an "auto MRI mode" that automatically switches to asynchronous pacing in the presence of a strong magnetic field, thus limiting the time in asynchronous mode to the MRI scan duration.

\section{Safe scanning of patients with MRI-conditional pacemakers}

The term "MRI-conditional" is applied to devices that pose no known hazards in a specific MRI environment under specific device and MRI scanner conditions. ${ }^{66}$ So, as the name implies, scanning patients with "MRI-conditional" pacemakers is safe only if a number of conditions are met. Such conditions are related to the MRI scanner, the MRI-conditional pacemaker (generator and leads), and patient characteristics. These are summarized in Table 2.

In practice, a number of steps should be followed when a patient with an MRI-conditional pacemaker is to undergo an MRI scan. ${ }^{10,67,68}$ Safe and effective scanning starts at the moment of scheduling, where the presence and close cooperation of several health care professionals during the scan (radiologist, MRI technologist, electrophysiology physician, and electrophysiology technician) should be guaranteed in advance.

Prior to the MRI examination, this team should exclude any contraindications, review the specific scanning conditions for the implanted pacemaker, and plan the procedure. A preMRI chest roentgenogram is useful to confirm electrode position and integrity, and check for MRI-conditional radiopaque markers if there are doubts regarding the implanted material (it should be noted that leads for which MRI-conditional status has been established a posteriori will not have such markers). Selecting the appropriate pacing mode starts with clinical assessment, reviewing the original indication for implantation, underlying rhythm and pacemaker dependency. Device interrogation prior to the examination is mandatory, except in patients carrying the Accent MRI conditional pacemaker with the optional hand-held Activator (these patients can undergo MRI after activation of preprogrammed device settings). However, even in those circumstances, device interrogation should ideally be performed to ensure that conditions have not changed significantly between preprogramming and the MRI scan. Device interrogation provides information on system integrity, percentage of pacing, programmed pacing rate, and AV interval, aiding in correct pacemaker programming prior to entering the MRI environment. In pacemaker-dependent patients, asynchronous mode should be selected. In patients with an underlying rhythm who are not bradycardic, asynchronous pacing competing with a ventricular rate could result in pacing during ventricular 
Table 2 Requirements for scanning patients with MRI-conditional pacemakers

\begin{tabular}{|c|c|c|c|c|c|}
\hline \multirow{2}{*}{\multicolumn{6}{|c|}{$\begin{array}{l}\text { Patient characteristics } \\
\text { - More than } 6 \text { weeks after pacemaker implantation }\end{array}$}} \\
\hline \multirow{2}{*}{\multicolumn{6}{|c|}{$\begin{array}{l}\text { - More than } 6 \text { weeks after pacemaker implantation } \\
\text { - Right or left pectoral implant (prepectoral or submuscular) }\end{array}$}} \\
\hline & & & & & \\
\hline \multicolumn{6}{|c|}{ - No other contraindications to MRI (eg, non-MRI-conditional abandoned leads) } \\
\hline \multicolumn{6}{|c|}{ - No lead adapters or extenders in situ } \\
\hline \multicolumn{6}{|c|}{ MRI scanner and scanning parameters } \\
\hline \multicolumn{6}{|c|}{ - Static magnetic field of I.5 T } \\
\hline \multicolumn{6}{|c|}{ - Cylindrical bore } \\
\hline \multicolumn{6}{|c|}{ - Maximum SAR of $2 \mathrm{~W} / \mathrm{kg}$} \\
\hline \multicolumn{6}{|c|}{ - Maximum head SAR of $3.2 \mathrm{~W} / \mathrm{kg}$} \\
\hline \multicolumn{6}{|c|}{ - Maximum gradient slew rate of $200 \mathrm{~T} / \mathrm{m}$ per second } \\
\hline \multicolumn{6}{|c|}{ Pacemaker model } \\
\hline & Medtronic ${ }^{\circledR}$ Revo $^{\mathrm{TM}}$, & Biotronik $^{\circledR}$ Evia $^{\mathrm{TM}}$ & St Jude ${ }^{\circledR}$ Accent ${ }^{\top M}$ & Boston Scientific $^{\circledR}$ & Sorin ${ }^{\circledast}$ KORA \\
\hline & Ensura $^{\mathrm{TM}}$ and Advisa ${ }^{\mathrm{TM}}$ & Entovis $^{\mathrm{TM}}$, Estella ${ }^{\mathrm{TM}}$ and & MRI pacemaker & Ingenio ${ }^{\mathrm{TM}}$ and & $100^{\mathrm{TM}} \mathrm{SR}$ and DR \\
\hline & Sure Scan ${ }^{\circledast}$ pacemakers & Ecuro $^{\mathrm{TM}}$ ProMRI $^{\circledR}$ & with Tendril TM & Advantio ${ }^{\mathrm{TM}}$ Image & pacemakers MRI \\
\hline & with CapSure ${ }^{\mathrm{TM}}$ leads & pacemakers with Safio ${ }^{\mathrm{TM}}$ & leads & Ready ${ }^{\circledR}$ pacemakers & with BEFLEX ${ }^{\mathrm{TM}}$ leads \\
\hline & & and Solia ${ }^{\mathrm{TM}}$ leads & & $\begin{array}{l}\text { with FINELINE }{ }^{\text {TM }} \\
\text { leads }\end{array}$ & \\
\hline MRI-conditional modes & All & & & & \\
\hline $\begin{array}{l}\text { Stable pacing capture } \\
\text { threshold values }\end{array}$ & & & $\checkmark$ & & \\
\hline $\begin{array}{l}\text { Capture threshold and } \\
\text { pulse width }\end{array}$ & $\leq 2.0 \vee @ 0.4 \mathrm{msec}$ & $\leq 2.0 \mathrm{~V} @ 0.4 \mathrm{msec}$ & $\leq 2.5 \vee 0.5 \mathrm{msec}$ & $\leq 3.0 \mathrm{~V} @ 0.4 \mathrm{msec}$ & $\leq 3.0 \mathrm{~V} @ 0.5 \mathrm{msec}$ \\
\hline Lead impedance & All & & & & \\
\hline 200-I,500 Ohms & & & & & \\
\hline $\begin{array}{l}\text { Battery charging status } \\
\text { at least } 30 \%\end{array}$ & & $\checkmark$ & & & \\
\hline $\begin{array}{l}\text { No diaphragmatic pacing } \\
\text { at } 5.0 \mathrm{~V} \text { at a pulse width }\end{array}$ & $\checkmark$ & & $\checkmark$ & & \\
\hline of $1.0 \mathrm{msec}$ & & & & & \\
\hline Scan zone restrictions & None & Exclusion zone between & None & None & Exclusion zone \\
\hline & & $\mathrm{Cl}$ and $\mathrm{TI} 2$ vertebrae & & & $\begin{array}{l}\text { between } \mathrm{Cl} \text { and } \\
\mathrm{TI} 2 \text { vertebrae }\end{array}$ \\
\hline Scan duration restrictions & None & $\begin{array}{l}\leq 30 \text { minutes for each } \\
\text { scan; total maximum } \\
\text { of } 10 \text { hours }\end{array}$ & None & None & None \\
\hline
\end{tabular}

Abbreviations: SAR, specific absorption rate; MRI, magnetic resonance imaging.

repolarization (" $\mathrm{R}$ on $\mathrm{T}$ phenomenon") potentially causing life-threatening arrhythmias. ${ }^{10}$ After adequate programming, the MRI mode is then turned on before the patient enters the room.

During the MRI scan, electrocardiography, pulse oximetry, and noninvasive blood pressure measurements (at least one of these) must be used for continuous hemodynamic monitoring. An external defibrillator (preferably capable of external pacing) should be readily available outside the MRI suite.

Once the scan is completed, the pacemaker's MRI mode should be turned off and the device interrogated and reprogrammed, preferably using the parameters stored prior to MRI scanning. Ideally, an electrophysiologist should supervise these steps. If these precautions are taken, scanning patients with MRI-conditional devices should be safe and relatively simple.

\section{Who should receive an MRI- conditional pacemaker?}

There is currently no consensus regarding who should receive an MRI-conditional pacemaker. Opinions range from universal adoption to almost complete dismissal, as some critics consider that the increased cost is unjustified and that conventional pacemakers can be safely scanned with appropriate precautions. ${ }^{13}$ From a clinical standpoint, the option for MRI-conditional pacemakers seems logical and beneficial in patients who have no other contraindications for MRI. However, adoption of this technology has been slower than expected and, in many centers, conventional pacemakers 
still account for the majority of implantations. The possible explanations for this slow uptake include the higher cost of MRI-conditional pacemakers, the lack of clear guidance on who should receive one of these devices, and the absence of long-term data on safety and durability. This later issue may be particularly important for the newer leads, since the introduced modifications may (at least theoretically) affect their performance characteristics, and their rates of long-term failure and fracture are essentially unknown. Other factors such as the limited range of choices in device manufacturer and lead fixation options may also contribute to their slow adoption (particularly in the USA), but these will probably wane with the recent and planned additions to the MRIconditional hardware portfolio.

Even if the universal adoption of MRI-conditional pacemakers seems desirable, the current financial constraints argue for selective implantation in patients who are more likely to need MRI in the future. Although some reasonable predictors can be put forward ${ }^{10,62,68,69}$ (Table 3), foreseeing the need for MRI on an individual basis is a challenging task.

Another option to consider is the implantation of MRIconditional leads together with a less expensive conventional pacemaker generator (that can be replaced by an MRI-conditional box if MRI is required). However, this strategy does not allow for emergency scanning and its costeffectiveness is uncertain.

\section{Unanswered questions and future directions}

Besides patient selection, other important questions have been raised by the arrival of MRI-conditional pacemakers. While their safety and effectiveness has been reasonably demonstrated, cost-effectiveness versus conventional pacemakers remains largely unknown.

This appraisal will ultimately depend on the impact of MRI-conditional technology on patient outcomes, which

Table 3 Compelling reasons for choosing an MRI-compatible pacemaker

Previous or planned MRI

Known comorbidities

- Present or previous malignancy

- Neurological disorder (eg, stroke, multiple sclerosis, seizures)

- Musculoskeletal disorder (eg, back pain, arthritis)

- Congenital heart disease

- Cardiomyopathy

Contraindication for iodinated contrast (known allergy, renal failure)

Planned surgery

Abbreviation: MRI, magnetic resonance imaging. may be difficult to demonstrate, since the advantage of these devices lies in the ability to perform diagnostic imaging, which may influence patient outcome, but only in an indirect and difficult to measure way. Other economic issues such as reimbursement for peri-scanning assessment and monitoring will also have to be considered. Legal implications may surface, especially in cases where, despite the availability of MRI-conditional pacemakers, a conventional device is implanted and the patient subsequently needs to undergo MRI. ${ }^{62}$ The impact on image quality will also have to be assessed, especially (but not only) in thoracic imaging.

Regarding hardware improvements, manufacturers will face the task of overcoming current device limitations such as restricted scan areas and specific absorption rate limits. Also, as 3.0 T imaging becomes more prevalent, it will also be important to have devices tested and approved for scanning at this magnetic field strength.

Meanwhile, the medical and scientific community should try to reach consensus and establish clear criteria for the implantation of these devices. Other important steps include consolidating the safety profile of this technology with evidence from large multicenter registries, and promoting the education of health care professionals on this subject (with an emphasis on multidisciplinary algorithms for safe and efficient scanning).

\section{Conclusion}

While the risk of performing MRI on patients with conventional pacemakers is probably lower than previously thought, patient safety can only be assured with the use of MRIconditional devices engineered to minimize the interactions between the pacemaker system and the MRI environment. Several MRI-conditional pacemakers are now available on the market and more will be introduced in the future. Currently available devices differ from each other in several aspects, including conditions of use and robustness of clinical trial data. Although this leap in pacing technology has opened the doors for this versatile imaging modality to a growing number of patients, widespread adoption will likely depend on pragmatic issues such as cost, definition of clear criteria for implanting an MRI-conditional device, and continuous education of health care professionals.

\section{Disclosure}

The authors report no conflicts of interest in this work.

\section{References}

1. IMV Medical Information Division, Inc. IMV Benchmark Report MR 2008. 
2. IMV Medical Information Division, Inc. IMV Benchmark Report MR 2012. Available from: http://www.imvinfo.com/index.asp?sec= mkt\&sub=omkt\&pag=def\&pid=90631. Accessed April 17, 2014.

3. Sutton R, Kanal E, Wilkoff BL, et al. Safety of magnetic resonance imaging of patients with a new Medtronic EnRhythm MRI SureScan pacing system: clinical study design. Trials. 2008;9:68.

4. Greenspon AJ, Patel JD, Lau E, et al. Trends in permanent pacemaker implantation in the United States from 1993 to 2009: increasing complexity of patients and procedures. J Am Coll Cardiol. 2012;60: 1540-1545

5. Mond HG, Proclemer A. The 11th world survey of cardiac pacing and implantable cardioverter-defibrillators: calendar year $2009-$ a World Society of Arrhythmia's project. Pacing Clin Electrophysiol. 2011;34:1013-1027.

6. Kalin R, Stanton MS. Current clinical issues for MRI scanning of pacemaker and defibrillator patients. Pacing Clin Electrophysiol. 2005;28:326-328.

7. Levine GN, Gomes AS, Arai AE, et al. Safety of magnetic resonance imaging in patients with cardiovascular devices: an American Heart Association scientific statement from the Committee on Diagnostic and Interventional Cardiac Catheterization, Council on Clinical Cardiology, and the Council on Cardiovascular Radiology and Intervention: endorsed by the American College of Cardiology Foundation, the North American Society for Cardiac Imaging, and the Society for Cardiovascular Magnetic Resonance. Circulation. 2007;116:2878-2891.

8. Roguin A, Schwitter J, Vahlhaus C, et al. Magnetic resonance imaging in individuals with cardiovascular implantable electronic devices. Europace. 2008;10:336-346.

9. Nazarian S, Beinart R, Halperin HR. Magnetic resonance imaging and implantable devices. Circ Arrhythm Electrophysiol. 2013;6: 419-428.

10. Shinbane JS, Colletti PM, Shellock FG. Magnetic resonance imaging in patients with cardiac pacemakers: era of "MR Conditional" designs. J Cardiovasc Magn Reson. 2011;13:63.

11. Beinart R, Nazarian S. Effects of external electrical and magnetic fields on pacemakers and defibrillators: from engineering principles to clinical practice. Circulation. 2013;128:2799-2809.

12. Luechinger R, Duru F, Scheidegger MB, Boesiger P, Candinas R. Force and torque effects of a 1.5-Tesla MRI scanner on cardiac pacemakers and ICDs. Pacing Clin Electrophysiol. 2001;24:199-1205.

13. Irnich W, Irnich B, Bartsch C, Stertmann WA, Gufler H, Weiler G. Do we need pacemakers resistant to magnetic resonance imaging? Europace. 2005;7:353-365.

14. Luechinger R, Duru F, Zeijlemaker VA, Scheidegger MB, Boesiger P, Candinas R. Pacemaker reed switch behavior in 0.5, 1.5, and 3.0 Tesla magnetic resonance imaging units: are reed switches always closed in strong magnetic fields? Pacing Clin Electrophysiol. 2002;25: 1419-1423.

15. Nijm GM, Swiryn S, Larson AC, Sahakian AV. Characterization of the magnetohydrodynamic effect as a signal from the surface electrocardiogram during cardiac magnetic resonance imaging. Comput Cardiol. 2006;33:269-272.

16. Birkholz T, Schmid M, Nimsky C, Schuttler J, Schmitz B. ECG artifacts during intraoperative high-field MRI scanning. J Neurosurg Anesthesiol. 2004; 16:271-276.

17. Gimbel JR. Unexpected pacing inhibition upon exposure to the $3 \mathrm{~T}$ static magnetic field prior to imaging acquisition: what is the mechanism? Heart Rhythm. 2011;8:944-945.

18. Gimbel JR. Unexpected asystole during 3T magnetic resonance imaging of a pacemaker-dependent patient with a 'modern' pacemaker. Europace. 2009;11:1241-1242.

19. Tandri H, Zviman MM, Wedan SR, Lloyd T, Berger RD, Halperin H. Determinants of gradient field-induced current in a pacemaker lead system in a magnetic resonance imaging environment. Heart Rhythm. 2008;5:462-468

20. Calcagnini $\mathrm{G}$, Triventi M, Censi F, et al. In vitro investigation of pacemaker lead heating induced by magnetic resonance imaging: role of implant geometry. J Magn Reson Imaging. 2008;28:879-886.
21. Mollerus M, Albin G, Lipinski M, Lucca J. Cardiac biomarkers in patients with permanent pacemakers and implantable cardioverterdefibrillators undergoing an MRI scan. Pacing Clin Electrophysiol. 2008;31:1241-1245.

22. Nordbeck P, Weiss I, Ehses P, et al. Measuring RF-induced currents inside implants: Impact of device configuration on MRI safety of cardiac pacemaker leads. Magn Reson Med. 2009;61:570-578.

23. Pictet J, Meuli R, Wicky S, van der Klink JJ. Radiofrequency heating effects around resonant lengths of wire in MRI. Phys Med Biol. 2002;47:2973-2985.

24. Fiek M, Remp T, Reithmann C, Steinbeck G. Complete loss of ICD programmability after magnetic resonance imaging. Pacing Clin Electrophysiol. 2004;27:1002-1004.

25. Baser K, Guray U, Durukan M, Demirkan B. High ventricular lead impedance of a DDD pacemaker after cranial magnetic resonance imaging. Pacing Clin Electrophysiol. 2012;35:e251-e253.

26. Luechinger R, Zeijlemaker VA, Pedersen EM, et al. In vivo heating of pacemaker leads during magnetic resonance imaging. Eur Heart J. 2005;26:376-383.

27. Langman DA, Goldberg IB, Finn JP, Ennis DB. Pacemaker lead tip heating in abandoned and pacemaker-attached leads at 1.5 Tesla MRI. J Magn Reson Imaging. 2011;33:426-431.

28. Martin ET, Sandler DA. MRI in patients with cardiac devices. Curr Cardiol Rep. 2007;9:63-71.

29. Kanal E, Gimbel JR. MR-conditional pacemakers. AJR Am J Roentgenol. 2012;198:W502-W503.

30. Zikria JF, Machnicki S, Rhim E, Bhatti T, Graham RE. MRI of patients with cardiac pacemakers: a review of the medical literature. AJR Am J Roentgenol. 2011;196:390-401.

31. Martin ET, Coman JA, Shellock FG, Pulling CC, Fair R, Jenkins K. Magnetic resonance imaging and cardiac pacemaker safety at 1.5-Tesla. J Am Coll Cardiol. 2004;43:1315-1324.

32. Sommer T, Vahlhaus C, Lauck G, et al. MR imaging and cardiac pacemakers: in-vitro evaluation and in-vivo studies in 51 patients at 0.5 T. Radiology. 2000;215:869-879.

33. Nazarian S, Roguin A, Zviman MM, et al. Clinical utility and safety of a protocol for noncardiac and cardiac magnetic resonance imaging of patients with permanent pacemakers and implantable-cardioverter defibrillators at 1.5 tesla. Circulation. 2006;114:1277-1284.

34. Mollerus M, Albin G, Lipinski M, Lucca J. Ectopy in patients with permanent pacemakers and implantable cardioverter-defibrillators undergoing an MRI scan. Pacing Clin Electrophysiol. 2009;32: 772-778.

35. Naehle CP, Meyer C, Thomas D, et al. Safety of brain 3-T MR imaging with transmit-receive head coil in patients with cardiac pacemakers: pilot prospective study with 51 examinations. Radiology. 2008;249: 991-1001

36. Pulver AF, Puchalski MD, Bradley DJ, et al. Safety and imaging quality of MRI in pediatric and adult congenital heart disease patients with pacemakers. Pacing Clin Electrophysiol. 2009;32:450-456.

37. Cohen JD, Costa HS, Russo RJ. Determining the risks of magnetic resonance imaging at 1.5 tesla for patients with pacemakers and implantable cardioverter defibrillators. Am J Cardiol. 2012;110:1631-1636.

38. Nazarian S, Hansford R, Roguin A, et al. A prospective evaluation of a protocol for magnetic resonance imaging of patients with implanted cardiac devices. Ann Intern Med. 2011;155:415-24.

39. Buendia F, Cano O, Sanchez-Gomez JM, et al. Cardiac magnetic resonance imaging at $1.5 \mathrm{~T}$ in patients with cardiac rhythm devices. Europace. 2011;13:533-538.

40. Sommer T, Naehle CP, Yang A, et al. Strategy for safe performance of extrathoracic magnetic resonance imaging at 1.5 tesla in the presence of cardiac pacemakers in non-pacemaker-dependent patients: a prospective study with 115 examinations. Circulation. 2006;114:1285-1292.

41. Roguin A, Zviman MM, Meininger GR, et al. Modern pacemaker and implantable cardioverter/defibrillator systems can be magnetic resonance imaging safe: in vitro and in vivo assessment of safety and function at 1.5 T. Circulation. 2004;110:475-482. 
42. Mollerus M, Albin G, Lipinski M, Lucca J. Magnetic resonance imaging of pacemakers and implantable cardioverter-defibrillators without specific absorption rate restrictions. Europace. 2010;12:947-951.

43. Strach K, Naehle CP, Muhlsteffen A, et al. Low-field magnetic resonance imaging: increased safety for pacemaker patients? Europace. 2010;12:952-960.

44. Naehle CP, Kreuz J, Strach K, et al. Safety, feasibility, and diagnostic value of cardiac magnetic resonance imaging in patients with cardiac pacemakers and implantable cardioverters/defibrillators at $1.5 \mathrm{~T}$. Am Heart J. 2011;161:1096-1105.

45. Boilson BA, Wokhlu A, Acker NG, et al. Safety of magnetic resonance imaging in patients with permanent pacemakers: a collaborative clinical approach. J Interv Card Electrophysiol. 2012;33:59-67.

46. Russo RJ. Determining the risks of clinically indicated nonthoracic magnetic resonance imaging at $1.5 \mathrm{~T}$ for patients with pacemakers and implantable cardioverter-defibrillators: rationale and design of the MagnaSafe Registry. Am Heart J. 2013;165:266-272.

47. Nazarian S, Halperin HR. How to perform magnetic resonance imaging on patients with implantable cardiac arrhythmia devices. Heart Rhythm. 2009;6:138-143.

48. Faris OP, Shein MJ. Government viewpoint: US Food and Drug Administration: Pacemakers, ICDs and MRI. Pacing Clin Electrophysiol. 2005;28:268-269.

49. Shinbane JS, Colletti PM, Shellock FG. MR in patients with pacemakers and ICDs: defining the issues. J Cardiovasc Magn Reson. 2007;9:5-13.

50. Gimbel JR. The safety of MRI scanning of pacemakers and ICDs: what are the critical elements of safe scanning? Ask me again at 10,000. Europace. 2010;12:915-917.

51. Jung W, Zvereva V, Hajredini B, Jackle S. Safe magnetic resonance image scanning of the pacemaker patient: current technologies and future directions. Europace. 2012;14:631-637.

52. Poole JE, Gleva MJ, Mela T, et al. Complication rates associated with pacemaker or implantable cardioverter-defibrillator generator replacements and upgrade procedures: results from the REPLACE registry. Circulation. 2010;122:1553-1561.

53. Neuzil P, Taborsky M, Rezek Z, et al. Pacemaker and ICD lead extraction with electrosurgical dissection sheaths and standard transvenous extraction systems: results of a randomized trial. Europace. 2007;9:98-104.

54. Expert Panel on MRS; Kanal E, Barkovich AJ, Bell C, et al. ACR guidance document on MR safe practices: 2013. J Magn Reson Imaging. 2013;37:501-530.

55. Shinbane JS, Colletti PM, Shellock FG. MR imaging in patients with pacemakers and other devices: engineering the future. JACC Cardiovasc Imaging. 2012;5:332-333.

56. Gray RW, Bibens WT, Shellock FG. Simple design changes to wires to substantially reduce MRI-induced heating at $1.5 \mathrm{~T}$ : implications for implanted leads. Magn Reson Imaging. 2005;23:887-891.
57. Bottomley PA, Kumar A, Edelstein WA, Allen JM, Karmarkar PV. Designing passive MRI-safe implantable conducting leads with electrodes. Med Phys. 2010;37:3828-3843.

58. Forleo GB, Santini L, Della Rocca DG, et al. Safety and efficacy of a new magnetic resonance imaging-compatible pacing system: early results of a prospective comparison with conventional dual-chamber implant outcomes. Heart Rhythm. 2010;7:750-754.

59. Wollmann CG, Thudt K, Vock P, Globits S, Mayr H. [Clinical routine implantation of a dual chamber pacemaker system designed for safe use with MRI: a single center, retrospective study on lead performance of Medtronic lead 5086MRI in comparison to Medtronic leads 4592-53 and 4092-58]. Herzschrittmacherther Elektrophysiol. 2011;22:233-236, 239-242. German.

60. Wilkoff BL, Bello D, Taborsky M, et al. Magnetic resonance imaging in patients with a pacemaker system designed for the magnetic resonance environment. Heart Rhythm. 2011;8:65-73.

61. Gimbel JR, Bello D, Schmitt M, et al. Randomized trial of pacemaker and lead system for safe scanning at 1.5 Tesla. Heart Rhythm. 2013;10:685-691.

62. Santini L, Forleo GB, Santini M; World Society of Arrhythmias. Evaluating MRI-compatible pacemakers: patient data now paves the way to widespread clinical application? Pacing Clin Electrophysiol. 2013;36:270-278.

63. Guidant. INGENIO MRI/ FINELINE II pacing system data collection in patients undergoing MRI (INFINITE-MRI). Available from: http:/clinicaltrials.gov/ct2/show/NCT01890512. NLM identifier: NCT01890512. Accessed January 13, 2014.

64. Wollmann CG, Steiner E, Vock P, Ndikung B, Mayr H. Monocenter feasibility study of the MRI compatibility of the Evia pacemaker in combination with Safio S pacemaker lead. J Cardiovasc Magn Reson. 2012;14:67.

65. Biotronik. ProMRI study of the Entovis pacemaker system. Available from: http://clinicaltrials.gov/show/NCT01761162. NLM identifier: NCT01761162. Accessed January 13, 2014.

66. Shellock FG, Woods TO, Crues JV 3rd. MR labeling information for implants and devices: explanation of terminology. Radiology. 2009;253:26-30.

67. Lobodzinski SS. Recent innovations in the development of magnetic resonance imaging conditional pacemakers and implantable cardioverter-defibrillators. Cardiol J. 2012;19:98-104.

68. Ahmed FZ, Morris GM, Allen S, Khattar R, Mamas M, Zaidi A. Not all pacemakers are created equal: MRI-conditional pacemaker and lead technology. J Cardiovasc Electrophysiol. 2013;24:1059-1065.

69. Cronin EM, Mahon N, Wilkoff BL. MRI in patients with cardiac implantable electronic devices. Expert Rev Med Devices. 2012;9: 139-146.
Medical Devices: Evidence and Research

\section{Publish your work in this journal}

Medical Devices: Evidence and Research is an international, peerreviewed, open access journal that focuses on the evidence, technology, research, and expert opinion supporting the use and application of medical devices in the diagnosis, treatment and management of clinical conditions and physiological processes. The identification of novel
Dovepress

devices and optimal use of existing devices which will lead to improved clinical outcomes and more effective patient management and safety is a key feature. The manuscript management system is completely online and includes a quick and fair peer-review system. Visit http://www. dovepress.com/testimonials.php to read real quotes from authors. 